\title{
Poder germinativo de sementes de capim-annoni-2 (Eragrostis plana Ness) recuperadas em fezes de bovinos
}

\section{Celso Augusto Vargas Lisboa', Renato Borges de Medeiros ${ }^{1}$, Eduardo Bohrer de Azevedo', Harold Ospina Patino', Silvane Barcelos Carlotto', Renata Porto Alegre Garcia1}

${ }^{1}$ Faculdade de Agronomia, UFRGS, Caixa Postal 15100, CEP: 90001-970, Porto Alegre, RS.

RESUMO - Objetivou-se com este trabalho avaliar o efeito do processo de digestão de bovinos sobre o poder germinativo de sementes de capim-annoni-2 (Eragrostis plana Ness) recuperadas nas fezes. As sementes (6 g, 27.273 sementes) foram colocadas no saco ventral do rúmem de oito novilhos fistulados, mantidos em gaiolas para ensaios metabólicos. Quarenta e três por cento das sementes fornecidas aos animais foram recuperadas nas fezes: aquelas recuperadas nos três primeiros dias corresponderam a 97,2\% da quantidade de sementes fornecidas. Somente $7,2 \%$ das sementes recuperadas, equivalente a $3,1 \%$ da quantidade de sementes fornecidas, apresentaram viabilidade. O tempo de permanência no trato digestivo foi a principal causa do desaparecimento das sementes consumidas e da perda de seu poder germinativo. A ausência de sementes de capim-annoni-2 nas fezes ocorre a partir do oitavo dia após a ingestão, assim, bovinos devem permanecer em quarentena por sete dias em área livre de capim-annoni-2 para limpeza do trato digestivo.

Palavras-chave: campo natural, dispersão de invasoras, ingestão de sementes, invasão biológica, transporte de sementes

\section{Germination of capim-annoni-2 (Eragrostis plana Ness) seeds recovered in bovine feces}

\begin{abstract}
This work was carried out with the objective of evaluating the effect of the bovine digestion process on the germination capacity of the capim-annoni-2 (Eragrostis plana Ness) seeds recovered in feces. The seeds (6 g, 27,273 seeds) were placed in a ruminal ventral sack of eight fistulated steers kept in pen trial. Forthy-three percent of the offered seeds were recovered in the feces. Seeds recovered in the first three days corresponded to $97.2 \%$ of the offered seeds. Only $7.2 \%$ of the recovered seeds germinated and represented $3.1 \%$ of the offered seeds. The permanence time in the digestive trait was the main cause for the disappearance of consumed seeds and for the loss in their germination capacity. The absence of capim-annoni-2 seeds in the feces occurs in the eighth day after ingestion, then, bovines should be kept in quarantine for seven days in an area free of capim-annoni-2 seeds to clean their digestive trait.
\end{abstract}

Key Words: biological invasion, natural grassland, seed ingestion, seed transport, weed dispersion

\section{Introdução}

As pastagens naturais são a base alimentar dos rebanhos do Rio Grande do Sul, todavia, a produção de forragem nesse recurso natural tem reduzido com a contínua expansão do capim-annoni-2 (Eragrostis plana Nees), gramínea cespitosa e perene de ciclo estival de origem africana (Reis \& Coelho, 2000). Por apresentar baixo valor nutritivo, ser rejeitada pelos animais e produzir grande quantidade de sementes, essa espécie tornou-se uma invasora de difícil controle na região. Estima-se que, atualmente, a área invadida seja de aproximadamente um milhão de hectares (Medeiros et al., 2004b).
Entre as recomendações de combate ao capim-annoni-2, a prevenção da sua expansão para áreas ainda não infestadas é medida prioritária. A contaminação de outras áreas ocorre basicamente por meio das fezes (endozoocoria) (Bray et al., 1998). Por ser o principal e por sua eficácia em estabelecer novas populações de plantas, esse mecanismo tem sido estudado por vários autores (Simão Neto et al., 1987; Jones \& Simão Neto, 1987; Gardener et al., 1993; Malo \& Suáres, 1995; Andrews, 1995).

Sementes pequenas de espécies de forrageiras se mantém viáveis depois de passarem pelo trato digestivo de ruminantes (Simão Neto et al., 1987; Gardener et al., 1993; Machado et al., 1997; Bray et al., 1998). Andrews (1995) 
verificou que sementes de Sporobolus indicus var. major e $S$. pyramidalis fornecidas a bovinos foram recuperadas nas fezes até o sétimo dia em um experimento e até o quarto dia, em outro. Uma fração de $41 \%$ das sementes de S. pyramidalis e $S$. natalensis fornecidas aos bovinos foi resgatada nas fezes (Bray et al., 1998) e, dessas sementes, $79 \%$ eram viáveis, representando $28 \%$ das sementes fornecidas. A presença de plântulas de capim-annoni- $2 \mathrm{em}$ fezes de bovinos em campo nativo do Rio Grande do Sul evidencia que uma fração das sementes de capim-annoni-2 ingeridas pelos bovinos passa pelo trato digestivo sem perder a viabilidade (Medeiros \& Focht, 2007).

Objetivou-se com este trabalho determinar o tempo de passagem pelo trato digestivo, a porcentagem resgatada nas fezes e, destas sementes resgatadas, a porcentagem de sementes viáveis de capim-annoni-2 fornecidas a novilhos de corte.

\section{Material e Métodos}

A fase experimental envolvendo o fornecimento de sementes de capim-annoni-2 aos animais foi realizada no Laboratório de Ensino Zootécnico do Departamento de Zootecnia da Faculdade de Agronomia da UFRGS, em Porto Alegre, no período de 8 a 13 de maio de 2006.

Utilizaram-se sementes de capim-annoni- 2 colhidas manualmente em fevereiro de 2006. As sementes foram secas lentamente em sacos de algodão pendurados em ambiente ventilado sem controle de temperatura e umidade durante duas semanas. Posteriormente, foram retiradas as impurezas utilizando-se peneiras e soprador do tipo De Leo até obtenção do peso médio de mil sementes de $0,21 \mathrm{~g}$ (Medeiros et al., 2004a), característico da espécie. O teste de germinação foi realizado de acordo com as Regras para Análise de Sementes (RAS), estabelecido pelo Ministério da Agricultura, Pecuária e Abastecimento (MARA, 1992), em 20 de março de 2006, e os resultados indicaram taxa de germinação de $90 \%$. Após o teste de germinação, as sementes foram mantidas em geladeira a $5^{\circ} \mathrm{C}$ até a data inicial do experimento.

No experimento, utilizaram-se oito novilhos machos castrados fistulados, mestiços Angus $\times$ Nelore $\times$ Charolês, com 18 meses de idade e peso médio de $242 \mathrm{~kg}$. Os animais foram mantidos confinados em gaiolas metabólicas, com dieta composta de feno da gramínea capim-bermuda cv. Tifton-85 (Cynodon spp., híbrido estéril entre PI 290884 da África do Sul e Tifton-68 [C. nlemfuensis Vanderryst]) com digestibilidade in vivo da matéria seca de 55\%. Após período de adaptação de dez dias, foram colocados $6 \mathrm{~g}$ de sementes (27.273 sementes) no saco ventral do rúmen dos animais. A quantidade de sementes que passaram inteiras pelo trato digestivo foi determinada em amostras homogêneas de $500 \mathrm{~g}$ de fezes da quantidade total excretada por dia, coletadas às $9 \mathrm{~h}$, durante cinco dias consecutivos, no período de 8 a 12 de maio de 2006. O consumo médio de matéria seca dos animais foi de $2,7 \%$. As quantidades de sementes recuperadas nas amostras foram ajustadas para $o$ total de fezes recuperadas por novilho. As amostras foram armazenadas em geladeira a $5^{\circ} \mathrm{C}$ por uma semana até o início do processo de limpeza e separação das sementes.

O processo de limpeza das sementes recuperadas foi realizado em três fases: 1) as amostras úmidas foram colocadas sobre peneiras metálicas com furos de $0,43 \mathrm{~mm}$ diâmetro (código comercial número 40, diâmetro do arame 33 BWG) para retenção das sementes e passagem dos restos de fezes por meio de lavagem com jato de água por 10 minutos. Em seguida, foram armazenadas em geladeira até o final da limpeza; 2 ) as amostras contendo as sementes e os restos de fezes foram colocadas em estufa de ar forçado regulada para $30^{\circ} \mathrm{C}$, durante 10 dias, e posteriormente foram colocadas em soprador tipo De Leo para separação, por peso gravimétrico, das sementes de capimannoni-2 dos fragmentos das fezes; 3 ) na última fase, as sementes foram examinadas e selecionadas com o uso de microscópio. Foram consideradas sementes recuperadas aparentemente viáveis aquelas com tegumento intacto contendo ou não embrião.

As quantidades de sementes recuperadas no primeiro dia foram suficientes para semear 100 sementes por repetição (novilho), em caixas germibox, conforme determinação da RAS. A quantidade das sementes recuperadas nos dias subseqüentes não foi suficiente para semear 100 sementes por repetição conforme recomenda a RAS. As sementes dos dias 4 e 5 não apresentaram viabilidade.

Os dados de recuperação das sementes excretadas nos cinco dias consecutivos apresentaram tendências dos tipos exponenciais negativas. Essa função tem sido utilizada para descrever dados da mesma natureza, como os obtidos em estudos de longevidade de sementes enterradas no perfil do solo em diversos tempos de exumação (Murdock \& Ellis, 2000; Medeiros et al., 2006). Com base nessas experiências, utilizou-se a equação exponencial negativa simples, com duas constantes e uma variável, para descrever a quantidade de sementes excretadas nos cinco dias consecutivos. Essa equação serviu de modelo para simular a excreção de sementes que poderia ocorrer a partir do quinto dia, a fim de se estabelecer o dia em que não se registrou a presença de sementes nas fezes. 
O delineamento experimental utilizado foi em bloco completamente casualisado, com oito repetições (animais). Utilizou-se o programa estatístico "Sigma Plot" para o ajuste do modelo exponencial negativo dos dados de sementes excretadas. O desvio-padrão foi utilizado para descrever a variação das variáveis sementes excretadas e germinadas.

\section{Resultados e Discussão}

O número de sementes recuperadas nas fezes apresentou variação entre animais, embora estes animais tenham sido selecionados por raça, peso e idade e manejados em gaiolas (Tabela 1). Essas variações também foram observadas por Ocumpaugh et al. (1993). De um total de 27.373 sementes (6 g) de capim-annoni-2 colocadas na fístula de novilhos, uma quantidade estimada de 11.734 intactas foi recuperada nas fezes (Tabela 1), o que representa $43 \%$ da quantidade fornecida aos animais. A passagem de sementes inteiras pelo trato digestivo de ruminantes tem sido observada em espécies de gramíneas cultivadas e nativas. Valores semelhantes foram encontrados por vários autores (Simões Neto et al., 1987; Jones \& Simão Neto, 1987; Bray et al., 1998). Simões Neto et al. (1987) verificaram que 22\% das sementes de Brachiaria decumbens Stapf - Poaceae e $38 \%$ de Axonopus affinis Chase - Poaceae passaram intactas pelo trato digestivo de bovinos. $\mathrm{O}$ resgate médio de sementes de Pasplum notatum Flueggé var. saurae Parodi - Poaceae cv. Pensacola - Poaceae, A. affinis, Trifolium semipilosum Fresen. - Fabaceae cv. Safari e Stylosanthes scraba Vog. - Fabaceae cv. Seca fornecidas a ovinos foi de $10 \%$ em dieta de baixa qualidade e $28 \%$ em dietas de média e alta qualidade (Jones \& Simão Neto, 1987). Esses autores verificaram também que a proporção de sementes fornecidas não influenciou a porcentagem de sementes recuperadas. Bray et al. (1998) registraram recuperação de $41 \%$ de sementes de Sporobolus pyramidalis (P.Beauv. - Poaceae) e S. natalensis (Steud.) T.Durand \& Schinz - Poaceae) em fezes de bovinos. Neste estudo, o percentual de recuperação de sementes de capim-annoni-2 foi bastante semelhante, o que está relacionado à semelhança em tamanho das sementes dessas duas espécies. Por serem muito pequenas, com dimensões de 1,0 $\mathrm{mm}$ de comprimento e 0,5 mm de largura (Medeiros et al., 2004a), possivelmente as sementes desta invasora não sofreram a ação da maceração durante o processo de ruminação. Essa ação, entretanto, pode ocorrer em frações de forragem com dimensões superiores a 1,7 e 2,3 mm em animais jovens e adultos, respectivamente (Van Soest, 1994).

O número de sementes excretadas nos três primeiros dias representou 97,2\% (Tabela 1). No quinto dia, foram excretadas somente 89 sementes, equivalentes a $0,8 \%$ do total (Tabela 1). Esperava-se, no entanto, que no quinto dia todas as sementes tivessem passado pelo trato digestivo, conforme registrado em $P$. virgatum L. (Ocumpaugh et al., 1993), em S. pyramidalis e $S$. natalensis (Bray et al., 1998) e em capim-touceirinha (S. indicus (L.) R. Br. var. major (Buse) Baaijens - Poaceae). Em outros trabalhos com gramíneas, a presença de sementes nas excreções foi registrada até o sétimo dia após a ingestão por ruminantes (Andrews, 1995).

Em razão da amplitude de dias de excreção, que varia de 4 a 7 dias, procurou-se determinar por quantos dias, além do quinto, ainda seriam excretadas sementes de capim-annoni-2 nas fezes de bovinos. Para isso, os valores de sementes recuperadas foram testados em várias funções matemáticas. Uma função exponencial simples negativa foi a que melhor descreveu os dados de resgate de sementes de capimannoni-2 (Figura 1). A partir desta função, estimou-se a quantidade de sementes excretadas até o dia de excreção zero, ou seja, o oitavo dia (Figura 2; Tabela 2). Os dados obtidos nesta simulação para o primeiro, segundo e terceiro dias foram muito próximos dos observados e indicaram que $99,0 \%$ das sementes foram excretadas (Tabela 2), valor apenas $1,8 \%$ superior ao observado. A quantidade excretada até o sétimo dia, calculada pelo modelo exponencial, resultou em 174 sementes a menos que o valor observado até o

Tabela 1 - Número e porcentagem de sementes recuperadas e germinadas, e porcentagens de sementes recuperada em relação a ingerida (R-I), germinada em relação a recuperada (G-R) e germinada em relação a ingerida (G-I) de capim-annoni-2 nas fezes de novilhos durante três ou cinco dias após serem colocadas em fístula ruminal

\begin{tabular}{|c|c|c|c|c|c|c|c|}
\hline \multirow[t]{2}{*}{ Dias } & \multicolumn{2}{|c|}{ Recuperadas } & \multicolumn{2}{|c|}{ Germinadas } & \multirow{2}{*}{$\begin{array}{c}\text { R-I } \\
\%\end{array}$} & \multirow{2}{*}{$\begin{array}{c}\text { G-R } \\
\%\end{array}$} & \multirow{2}{*}{$\begin{array}{c}\text { G-I } \\
\%\end{array}$} \\
\hline & $\mathrm{n}^{\mathrm{o}}$ & $\%$ & $\mathrm{n}^{\mathrm{o}}$ & $\%$ & & & \\
\hline 1 & $9.120 \pm 1.602$ & 77,7 & $793 \pm 460$ & 93,5 & 33,4 & 6,76 & 2,91 \\
\hline 2 & $1.917 \pm 572$ & 16,3 & $50 \pm 33$ & 5,9 & 7,0 & 0,42 & 0,18 \\
\hline 3 & $377 \pm 131$ & 3,2 & $5 \pm 9$ & 0,6 & 1,4 & 0,04 & 0,02 \\
\hline 4 & $231 \pm 119$ & 2,0 & - & - & 0,8 & - & - \\
\hline 5 & $89 \pm 54$ & 0,8 & - & - & 0,3 & - & - \\
\hline Total & 11.734 & 100 & 849 & 100 & 43,0 & 7,23 & 3,11 \\
\hline
\end{tabular}


quinto dia. Por apresentar coeficiente de determinação de 0,99, a função exponencial é adequada (Figura 1). Com base nos dados calculados, verificou-se que as últimas sementes foram excretadas no dia 7 (Tabela 2). A quantidade recuperada seria de apenas uma semente, valor inexpressivo se calculado em porcentagem $(0,004 \%)$.

De acordo com Bray et al. (1998), sementes de $S$. pyramidalis e $S$. natalensis, semelhantes às de capimannoni-2, fornecidas a bovinos foram todas excretadas no quarto dia depois de ingeridas. Conforme esses autores, os animais devem permanecer em quarentena por quatro dias em área livre de $S$. pyramidalis para limpar o trato

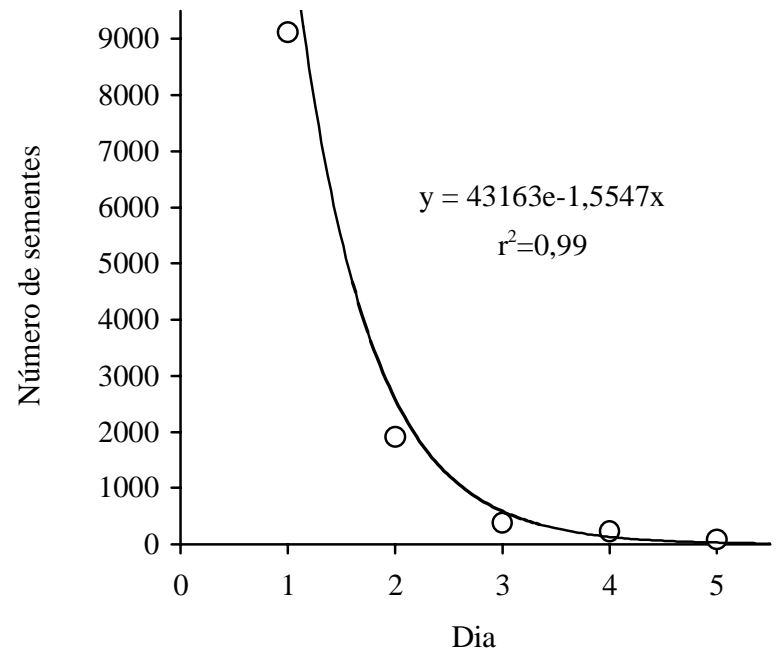

Figura 1 - Sementes de capim-annoni-2 recuperadas nas fezes de novilhos 5 dias após ingestão.

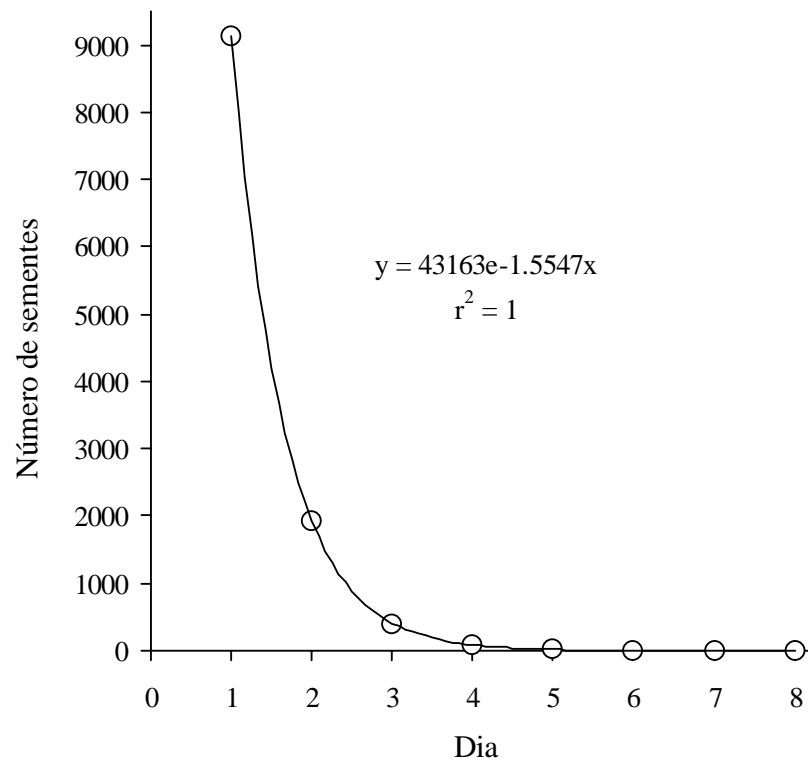

Figura 2 - Função exponencial do número de sementes de capimannoni-2 recuperadas nas fezes de novilhos, obtida a partir da exponencial da Figura 1, simulada para 8 dias após ingestão.
Tabela 2 - Número observado e calculado de sementes de capimannoni-2 em fezes de novilhos

\begin{tabular}{|c|c|c|c|}
\hline \multirow[b]{2}{*}{ Dias } & \multicolumn{2}{|c|}{ Sementes recuperadas ${ }^{1}$} & \multirow{2}{*}{$\begin{array}{c}\text { Diferença } \\
\text { Recuperadas } \\
\text { calculadas }\end{array}$} \\
\hline & $\begin{array}{c}\text { Número } \\
\text { observado }\end{array}$ & $\begin{array}{l}\text { Número } \\
\text { calculado }\end{array}$ & \\
\hline 1 & 9.120 & 9.119 & -1 \\
\hline 2 & 1.917 & 1.926 & 9 \\
\hline 3 & 377 & 407 & 30 \\
\hline 4 & 231 & 86 & 145 \\
\hline 5 & 89 & 18 & -71 \\
\hline 6 & - & 4 & - \\
\hline 7 & - & 1 & - \\
\hline 8 & - & 0 & - \\
\hline Total & 11.734 & 11.560 & -174 \\
\hline
\end{tabular}

${ }^{1}$ A regressão linear entre os valores de sementes recuperadas observadas e calculadas para os primeiros cinco dias apresentou $\mathrm{r}^{2}=0,9995$ e $\mathrm{y}=\mathrm{x}$.

digestivo. Andrews (1995), trabalhando com a mesma espécie de gramínea em um experimento, obteve resultados similares, mas em outro experimento com novilhas leiteiras da raça Friesian, esse autor verificou que as sementes foram excretadas até o sétimo dia.

Neste experimento, considerando os dados simulados pela função exponencial negativa (Figura 1), sugere-se que os animais permaneçam em quarentena por sete dias em área livre de capim-annoni-2 para limpeza do trato digestivo. Do ponto de vista prático, enquanto outros estudos não forem realizados para comparação dos resultados, é recomendável observar o tempo de quarentena sugerido. Ao adquirir bovinos, especialmente de regiões infestadas de capim-annoni-2 no período de produção de sementes, de novembro a março (Reis \& Coelho, 2000), os produtores devem se atentar e não introduzir os animais em suas propriedades.

Do total de 11.734 sementes recuperadas nas fezes, 849 germinaram em condições de laboratório (Tabela 1). Esse valor representou $7,2 \%$ do resgatado e $3,1 \%$ da quantidade de sementes fornecidas aos animais. Noventa e três por cento das sementes recuperadas no primeiro dia depois de colocadas nas fístulas ruminais germinaram, entretanto, apenas 5,9 e $0,6 \%$, respectivamente, das sementes recuperadas no segundo e terceiro dia germinaram.

As porcentagens de sementes germinadas em relação às recuperadas, de $6,8,0,4 \mathrm{e} 0,004$ no primeiro, segundo $\mathrm{e}$ terceiro dias, respectivamente, indicam grande perda da germinabilidade das sementes de capim-annoni-2 após passar pelo trato gastrointestinal de bovinos (Tabela 1). A sobrevivência de sementes ao passarem pelo trato digestivo dos ruminantes foi descrita por vários autores em estudos com espécies de gramíneas (Simão Neto et al., 1987; Gardener et al., 1993; Andrews, 1995; Bray et al., 1998) e leguminosas (Squella \& Carter, 1993; Machado et al., 
1997). A porcentagem de sementes de capim-annoni-2 viáveis recuperadas nas fezes dos animais foi inferior à registrada em outros trabalhos. Bray et al (1998) verificaram que $79 \%$ das sementes recuperadas de $S$. pyramidalis e $S$. natalensis eram viáveis, o que representa $28 \%$ do total de sementes fornecidas aos animais. Para S. Pyramidalis, Andrews (1995) verificou que apenas 19\% das sementes fornecidas aos bovinos são excretadas viáveis. Simão Neto et al. (1987) registraram 21 e $12 \%$ de sementes viáveis em B. decumbens e A. affinis, respectivamente.

Ocumpaugh et al. (1993) relataram que o poder germinativo de sementes de muitas espécies de gramíneas reduzem de forma linear conforme aumenta o tempo de permanência no rúmen. Esses autores observaram esse declínio em sementes de $P$. virgatum, $P$. coloratum L. e $P$. notatum. Redução linear da germinação de sementes de gramíneas foi observada também por Simão Neto et al. (1987). Nesta pesquisa, esta relação linear negativa do poder germinativo com o tempo de passagem pelo trato digestivo não foi registrada. Os valores de germinação das sementes recuperadas de capim-annoni-2 até o terceiro dia indicam ajuste exponencial negativo. Ocumpaugh et al. (1993), examinando outras espécies de gramíneas, como Schizachyrium scoparium (Michx.) Nash, Bouteloua curtipendula (Michx.) Torr., Botrichloa spp. e Setaria macrostacyia Kunth, verificaram baixa sobrevivência ou ausência de sementes viáveis após passarem pelo trato digestivo de ruminantes, e até mesmo quando recuperadas após 24 horas de ingestão. Possivelmente, as sementes de capim-annoni-2 estão sujeitas a alta degradabilidade ao passarem pelo trato digestivo de bovinos. Essa característica, no caso desta invasora, pode ser compensada pela elevada produção de sementes (Coelho, 1993) de pequeno tamanho, pelo alto poder germinativo e eficiente estabelecimento (Medeiros \& Focht, 2007).

Os resultados indicam que a perda do poder germinativo das sementes do capim-annoni-2 está relacionada ao tempo de permanência no trato gastrointestinal de ruminantes (Ocumpaugh et al., 1993), uma vez que sementes de pequeno tamanho, como as de capim-annoni-2, podem escapar do efeito destrutivo da maceração (Van Soest, 2004).
Significativa quantidade de sementes de capimannoni-2 sobreviveu após passar pelo trato gastrointestinal de bovinos. Essas sementes podem manter-se viáveis nas fezes durante vários meses, conforme registrado em várias espécies de gramíneas (Gardener et al., 1993). Simão Neto \& Jones (1986) determinaram o efeito da incubação de sementes de $B$. decumbens e A. affinis em fezes de bovinos por períodos de 2, 7 e 21 dias combinado com as temperaturas de $10^{\circ} \mathrm{C}, 35 / 10^{\circ} \mathrm{C}$ e $35^{\circ} \mathrm{C}$ e verificaram que as menores temperaturas preservaram a viabilidade das sementes, pois, no caso de A. affinnis, na incubação a $10^{\circ} \mathrm{C}$, todas as sementes sobreviveram. Este efeito foi independente do período de armazenagem. Entretanto, ainda é necessário estudar a sobrevivência das sementes no micro-ambiente das fezes, pois as informações existentes permitem inferir que uma fração de sementes sobrevive por algum tempo nas fezes.

Bray et al. (1998) relataram que 19 a 160 sementes de S. pyramidalys foram encontradas por quilo de fezes úmidas de bovinos coletadas no inverno, mesmo quando pequenas quantidades de sementes estavam presentes no campo. Andrews (1995) encontrou expressivo número de sementes de $S$. pyramidalis em amostras de fezes de bovinos e estimou que os animais consumiram $2.200 \mathrm{e}$ 8.300 sementes/dia em áreas com média e alta infestação, respectivamente. Uma vez que as panículas dessa espécie não são palatáveis, o autor considerou o consumo expressivamente grande. Neste estudo, considerando os valores médios de sementes excretadas e germinadas de capimannoni-2, a partir do fornecimento de $6 \mathrm{~g}$ de sementes, estimaram-se as quantidades potenciais de sementes excretadas e germinadas de um bovino adulto (UA), em cinco dias, para consumos crescentes de sementes (Tabela 3).

Considerando que um novilho consome $10 \mathrm{~g} / \mathrm{dia}$ ou 45.455 sementes de capim-annoni-2 com elevada qualidade fisiológica, tem-se um potencial de sementes excretadas/ novilho de 19.545 e de 1.414 sementes germinadas/novilho ou 2.629 germinadas/unidade animal (Tabela 3). Como a ingestão é um processo contínuo, esse número de sementes viáveis representa o potencial diário de dispersão de

Tabela 3 - Peso e número de sementes fornecidas por novilho, número de sementes recuperadas por novilho e germinadas por novilho e unidade animal (UA) em fezes de bovinos

\begin{tabular}{cccc}
\hline \multicolumn{2}{c}{ Fornecida/novilho } & Recuperada/novilho & \multicolumn{2}{c}{ Germinada/novilho } \\
$\mathrm{g}$ & Número & Número & Número \\
\hline 6 & 27.273 & 11.727 & 849 \\
10 & 45.455 & 19.545 & 1.414 \\
50 & 22.723 & 97.727 & 7.068 \\
\hline
\end{tabular}


sementes. Sabe-se que o ambiente físico-químico das fezes preserva uma fração significativa de sementes (Gardener et al., 1993). No caso do capim-annoni-2, se as fezes de um bovino adulto preservarem $20 \%$ de sementes viáveis até a primavera, serão obtidas 526 sementes com potencial de germinação. Considerando que $50 \%$ dessas plântulas se estabelecem, em média, 263 plantas serão estabelecidas por dia. Essa projeção indica elevado potencial de invasão do capim-annoni-2 em situações em que animais de regiões com campos com alta infestação e em fase de produção de sementes são transportados para campos ou regiões ainda livres desta invasora.

Esse potencial de expansão é ainda maior se, no caso do capim-annoni-2, as sementes permanecerem viáveis no trato digestivo de bovinos por três dias ou mais. Esse tempo possibilita que as sementes se dispersem a grandes distâncias aumentando a abrangência da invasão de novas áreas ou regiões.

\section{Conclusões}

Alta proporção de sementes de capim-annoni-2 é excretada nas fezes de bovinos, no entanto, pequena fração dessas sementes apresenta viabilidade. A digestão é a principal causa do desaparecimento das sementes fornecidas aos animais e da perda de seu poder germinativo. A ausência de sementes de capim-annoni-2 nas fezes no oitavo dia indica que o período de quarentena para limpeza do trato digestivo de bovinos recebendo forragem sem sementes da invasora é de sete dias.

\section{Agradecimentos}

Ao CNPq, à CAPES e à UFRGS, pelo apoio financeiro.

\section{Literatura Citada}

ANDREWS, T.S. Dispersal of seeds of giant Sporobolus spp. after ingestion by grazing cattle. Australian Journal of Experimental Agriculture, v.35, n.3, p.353-356, 1995.

COELHO, R.W. Diagnóstico do problema e retrospectiva da pesquisa realizada com capim annoni 2 no CNPO e CPATB. Bagé: Embrapa Pecuária Sul, 1993. p.53-69. (Documento, 7).

BRAY, S.G.; CAHILL, L.; PATON, C.J. et al. [1998]. Can cattle spread giant rats tail grass seed (Sporobolus pyamidalys) in their feces? Disponível em: <http//www.regional.org.au/ au/asa/1998/6/030bray.htm> Acesso em: 4/4/2005.

GARDENER, C.J.; MCIVOR, J.G.; JANSEN, A. Passage of legume and grass seeds through the digestive tract of cattle and their survival in feces. Journal of Applied Ecology, v.30, n.2, p.63-74, 1993.

JONES, R.M.; SIMÃO NETO, M. Recovery of pasture seed ingested by ruminants. 3 . The effects of the amount of seed in the diet and of diet quality on seed recovery from sheep. Australian
Journal of Experimental Agriculture, v.27, n.2, p.253-256, 1987.

MACHADO, L.A.Z.; DENARDIN, R.N.; JACQUES, A.V.A. et al. Porcentagem de germinação e dureza do tegumento de sementes de três espécies forrageiras recuperadas em fezes ovina. Revista da Brasileira de Zootecnia, v.26, n.1, p.42-45, 1997.

MALO, J.E.; SUÁRES, F. Establishment of pasture on cattle dung: the role of endozoochorous seeds. Journal of Vegetation Science, v.6, p.169-174, 1995.

MEDEIROS, R.B.; FOCHT, T. Invasão, prevenção, controle e utilização do capim-annoni-2 (Eragrostis Plana Ness) no Rio Grande do Sul. Pesquisa Agropecuária Gaúcha, v.13, n.1-2, p.105-114, 2007.

MEDEIROS, R.B.; FOCHT, T.; FERREIRA, N.R. et al. Longevidade de sementes de Eragrostis plana Nees em um solo de campo natural. In: REUNIÓN DEL GRUPO TÉCNICO REGIONAL DEL CONO SUR EN MEJORAMIENTO Y UTILIZACIÓN DE LOS RECURSOS FORRAJEROS DEL ÁREA TROPICAL Y SUBTROPICAL - GRUPO CAMPOS, 30., 2004, Salto, Uruguai. Memorias... Salto: Universidad de la Republica, 2004a. p.213-214.

MEDEIROS, R.B.; FOCHT, T.; FREITAS, M.R. et al. Longevidade de sementes de capim-annoni-2 enterradas em solo de campo natural. In: REUNIÃO DO GRUPO TÉCNICO EM FORRAGEIRAS DO CONE SUL - GRUPO CAMPOS, 21., 2006, Pelotas. Palestras e Resumos... Pelotas: Universidade Federal de Pelotas, 2006. (CD-ROM).

MEDEIROS R.B.; PILLAR, V.P.; REIS, J.C.R. Expansão de Eragrostis plana Ness. (Capim-Annoni-2) no Rio Grande do Sul e indicativos de controle In: REUNIÓN DEL GRUPO TÉCNICO REGIONAL DEL CONO SUR EN MEJORAMIENTO Y UTILIZACIÓN DE LOS RECURSOS FORRAJEROS DEL ÁREA TROPICAL Y SUBTROPICAL - GRUPO CAMPOS, 30., 2004, Salto, Uruguai. Memorias... Salto: Universidad de la Republica, 2004b. p.211-212.

MINISTÉRIO DA AGRICULTURA E REFORMA AGRÁRIA MARA. Regras para análise de sementes. 1.ed. Brasília: SNDA/DNDV/CLAV, 1992. 365p.

MURDOCK, A.J.; ELLIS, R.H. Dormancy, viability and longevity. In: FENNER, M. (Ed.) Seeds: the ecology of regeneration in plant communities. Wallingford: CAB International, 2000. p. 183-214.

OCUMPAUGH, W.R.; STUTH, J.W.; ARCHER, S.R. Recovery and germination of switchgrass seed fed to cattle, In: INTERNTIONAL GRASSLAND COGRESS, 17., 1993, Glen Osmond, South Australia. Proceedings... Glen Osmond: The University of Adelaide, Waite Agricultural Institute, 1993. p.316-319.

REIS, J.C.L. Capim Annoni 2: origem, morfologia, características, disseminação. Bagé: Embrapa Pecuária Sul, 1993. p.5-24. (Documento, 7).

REIS, J.C.L.; COELHO, R.W. Controle do capim annoni-2 em campos naturais e pastagens. Pelotas: Embrapa Clima Temperado, 2000. 21p. (Circular Técnica, 22).

SIMÃO NETO, M.; JONES, R.M. The effect of storage in cattle dung on viability of tropical pasture seeds. Tropical Grasslands, v.4, n.20, p.180-183, 1986.

SIMÃO NETO, M.; JONES, R.M.; RATCLIFF, D. Recovery of pasture seed ingested by ruminants. 1. Seed of six tropical pasture species fed to cattle, sheep and goats. Australian Journal of Experimental Agriculture, v.27, n.2, p.239-246, 1987.

SQUELLA, F.; CARTER, E.D. Significance of seed size and level of hard seededness on survival of medic ingested by sheep. In: INTERNTIONAL GRASSLAND COGRESS, 17., 1993, Glen Osmond, South Australia. Proceedings... Glen Osmond: The University of Adelaide, Waite Agricultural Institute, 1993. p.419-420.

Van SOEST, P.J. Nutritional ecology of the ruminant. 2.ed. Ithaca: Cornell University Press, 1994. 476p. 